\title{
The Persuit of Happiness: Notas desde el epicentro de la pandemia
}

\author{
Andrés Prieto \\ University of Colorado Boulder
}

Algunos meses atrás, fabriqué una mesa. Me tomé el tiempo de lijar todas las imperfecciones, redondear las esquinas y vitrificar la superficie. Una vez acabada, la llevé a mi habitación. Vivo en una casa vieja en uno de los barrios tradicionales de Denver. En sus más de cien años, esta casa ha tenido varias remodelaciones que la han dejado con algunos espacios peculiares. Uno de ellos es un recoveco largo y angosto que da a una pequeña ventana en mi habitación. Es lo suficientemente alto como para que yo pueda estar de pie ahí dentro, pero no mucho más; tendrá quizás dos metros de largo. Por años no supe qué hacer con él, hasta que decidí transformarlo en un rincón de escritura. A la mesa le añadí un pequeño librero y una lámpara. El lugar era acogedor y, más importante aún, uno de los pocos rincones en casa donde no había conexión a Internet. Sin embargo, hago clases en una ciudad cercana, y entre obligaciones familiares y laborales, escasamente pasé un día en mi nuevo escritorio. Hasta que llegó la pandemia. En marzo de este 2020, me encontraba en Chile, a la espera de que se me unieran mi mujer y mi hijo, cuando la conciencia de que esta vez iba en serio, de que esto no era un tiro de salva como el 2003 o el 2009, nos golpeó de pronto a todos. Italia cerraba regiones enteras; España entraba en cuarentena total. Los vuelos desde y hacia Chile empezaban a ser cancelados. Me vi obligado a abandonar compromisos y tomar uno de los últimos aviones de vuelta a casa. Cuando llegué, me encontré con un país presa del pánico. Productos como el papel higiénico o la comida enlatada habían desaparecido de los supermercados; las ventas de armas se habían disparado; las escuelas suspendían las clases y trataban de ingeniárselas para terminar el año escolar. Aliviado de estar entre los míos otra vez, pensé que quizás el confinamiento que se veía venir me permitiría, por fin, terminar el libro sobre José de Acosta en el que trabajo desde hace algunos años. No tenía que volver a hacer clases hasta agosto; podría sortear la pandemia en mi rincón que, ahora sí, iba a poder utilizar. El coronavirus me había regalado tiempo y yo, decidido a aprovecharlo, me he sentado en mi mesa de trabajo todos los días durante los últimos meses. Y sin embargo, no puedo escribir.
\end{abstract}


George Steiner dijo alguna vez que los libros que no escribimos son mucho más que una simple negación. Son, quizás, más determinantes que aquellos que sí logramos ver publicados. Nos definen no en un sentido público, sino más bien íntimamente. Nos acompañan como un miembro fantasma, como una presencia que nos obliga a preguntarnos por lo que pudo ser. Quizás, como dice Steiner, ese libro que no escribimos podría haber marcado una diferencia; quizás podría habernos permitido fracasar de mejor manera. El libro sobre Acosta no sería ni el primer ni el último libro que no termino. Por supuesto, no es que no escriba por flojera o desidia. Como el insomne que se prepara, contra toda esperanza, a dormir noche tras noche, yo repito todos los gestos de mi trabajo: revuelvo libros, consulto viejos documentos, tomo notas, diseño secciones. Incluso compongo párrafos. Y sin embargo, me encuentro incapaz de seguir el consejo que le doy a cada uno de mis estudiantes: escriba una página al día y defenderá su tesis en un año. Pero es que, ¡cuán poco sentido tiene el quehacer del historiador en momentos en que el mundo parece girar al revés! ¿Qué importancia pueden tener los debates entre teólogos o las maquinaciones de Claudio Aquaviva cuando uno ha visto las fotografías aéreas de las fosas comunes en New York? Los tiempos parecen reclamar un reportero u otro tipo de cronista, alguien capaz de transmitir la inmediatez del desastre y la urgencia del dolor. No a quien vive pensando el presente desde el pasado.

La historiadora italiana Gianna Pomata ha reflexionado sobre los paralelismos y diferencias entre nuestra pandemia y la Peste Negra de 1347. Otros han traído a colación la Gripe Española de 1918, una pandemia mucho más mortífera que la presente, según todas las indicaciones, pero que extrañamente apenas dejó marca alguna en la cultura popular. Por un tiempo, pensé que quizás la pandemia que más debería acercarse a esta era aquella otra que le tocó vivir a mi generación, la del VIH. Tal como el coronavirus, el VIH se ensañó con algunos de los grupos más marginalizados de nuestras sociedades. Tal como el coronavirus, el VIH nos obligó a cambiar la forma en que nos relacionábamos. Aquellos gestos tan básicos en nosotros, comunes a todos los primates (tocarnos, abrazarnos, acariciarnos, sentir y experimentar el cuerpo del otro como condición de necesidad de nuestro vínculo social) habían sido trastocados y vueltos mortíferos por el virus, al igual como ocurre ahora. Y sin embargo, al menos para aquellos que vimos en nuestra infancia cómo se extendía el VIH por el mundo y que nos iniciamos sexualmente en el momento en que aparecieron los retrovirales, el SIDA no fue una condena a muerte si uno tenía acceso a salud y medicamentos. Tal como ahora, en que nos encerramos en nuestras casas y monitoreamos la situación desde Internet; en que la enfermedad se ensaña con otros, con aquellos que trabajan en las fábricas empaquetadoras de carne, en los hospitales, en los supermercados, aquellos que nos traen las provisiones a la puerta de la casa, exponiendo sus vidas para que nosotros no tengamos que exponernos, nuestro privilegio siempre nos ha protegido. 
Recientemente tuve ocasión de examinar un gráfico de las muertes anuales en New York desde el siglo XIX hasta el presente. Dos cosas saltaban a la vista: La primera, es que las epidemias — representadas por picos de mortandad- se repetían cada pocos años, sobre todo desde 1840 en adelante. La segunda, es que el siglo XX aparecía como una curva descendente. Por supuesto, la explicación a este fenómeno se da en los avances médicos que ocurrieron en apenas una generación. En la década de 1880, Louis Pasteur demostró el origen microbiano de las enfermedades, creó el proceso de pasteurización y perfeccionó la técnica de la vacunación. Una de las máximas de Pasteur, que los descubrimientos accidentales solo pueden ser aprovechados por las mentes preparadas, se verificó poco después, en 1928, cuando el escocés Alexander Flemming notó que un hongo estaba interfiriendo con sus cultivos bacterianos. El descubrimiento de la naturaleza microbiana de las infecciones, las vacunas y los antibióticos (junto a avances urbanísticos y de salud pública, como la cloración del agua o la construcción de sistemas de alcantarillado en las ciudades) llevaron a una situación inédita en los casi 250 mil años de la especie humana: por primera vez teníamos armas efectivas para defendernos de nuestros más eficientes depredadores. Incluso en países pobres como Chile, un niño como yo, que nacía a finales del siglo XX, tenía más posibilidades de llegar a la edad adulta que de morir en la primera infancia, algo que no era cierto ni siquiera en las clases acomodadas dos generaciones antes. Cuando cumplí seis años, fui testigo de uno de los mayores logros colectivos de la humanidad: la erradicación de uno de nuestros enemigos más enconados, la viruela.

Pero nuestra victoria sobre la enfermedad significó olvidar a los muertos. O mejor, olvidar a la muerte. Sí, aún nacemos para morir y todos tenemos conciencia de ello. Pero ya no convivimos con la muerte. Ni siquiera la imaginamos como algo cercano. Es algo que ocurre en la vejez, una vejez que cada vez parece más larga y más lejana. Apenas cien años atrás, la gente experimentaba la muerte de forma muchísimo más próxima que nosotros. Las personas nacían y morían en sus casas, no en hospitales, y crecían rodeados de al menos otras dos generaciones. Ambos extremos de la vida eran parte de la experiencia de nuestros antepasados, muchos de los cuales llevaban el nombre de un hermano mayor muerto antes de que ellos mismos nacieran. Esas hermosas e inquietantes fotografías victorianas, en las que el cadáver del abuelo o de la madre muertos era bañado y vestido con sus mejores ropas para sentarlo en la mesa o colocarlo en otras poses cotidianas, rodeados por sus familiares, causarían horror hoy en día. La muerte ha dejado de ser un asunto familiar para ser un problema técnico, que ocurre no ya en el ámbito del hogar, sino en la asepsia de la sala del hospital. Ya no hay manos amorosas que bañen el cuerpo aún tibio mientras lloran su partida. En su lugar, un parte médico y trámites municipales; cementerios que se parecen más a un parque a orillas del 
mediterráneo que a un camposanto. Toda una industria empeñada en invisibilizar nuestro destino último.

Para nosotros, que vivimos protegidos por una serie de privilegios (de clase, económicos, raciales), el vernos encerrados en nuestras casas, imposibilitados de ver o tocar a nuestros amigos y familiares, mientras revisamos obsesivamente las tasas de contagio per cápita o el número total de enfermos, ha traído de vuelta no la realidad de la muerte, sino su posibilidad. Una enfermedad nueva, sin tratamiento conocido, ha saturado los sistemas hospitalarios y hecho saltar por los aires todas las defensas culturales que nos permitían pensar en la muerte como una ficción. Las imágenes dantescas que la prensa repite una y otra vez — camiones refrigerados estacionados junto a los hospitales, recintos deportivos transformados en morgues de emergencia, cuerpos apilados en hospitales de New York o pudriéndose en sus hogares en Guayaquil; residencias de ancianos donde al entrar los funcionarios municipales no encuentran un solo sobreviviente- han hecho añicos nuestra fantasía de haber triunfado sobre la enfermedad y la muerte. Recientemente $\mathrm{CNN}$ informaba con horror que algunos hospitales en Texas, abrumados por la cantidad de casos de COVID-19, estaban considerando enviar a los enfermos más graves a morir a sus casas. Con macabra ironía, la pandemia nos ha devuelto a un tiempo para el cual no tenemos las herramientas emocionales que nos permitan habitarlo. Es la otra cara del progreso: toda ganancia trae una pérdida.

\section{II}

Ya no sabemos convivir con la muerte, pero no siempre fue así. He pasado el último año leyendo cartas escritas por gente que vivió siglos antes de Pasteur y Flemming. Todos, o casi todos, jesuitas. Una sorprendente cantidad de estas cartas habla sobre la fragilidad del cuerpo humano: El hermano Pedro ha caído enfermo en Sevilla; se le solicita al destinatario que rece por él. Los colegas o amigos de los autores de estas cartas morían usualmente después de una larga y prolongada agonía, cuya duración era exhibida como prueba de la fortaleza espiritual del agonizante. Otras veces, el fin era repentino, como le ocurrió en 1593 a Alonso Sánchez, el principal enemigo político de Acosta, quien sufrió un infarto al día siguiente de ser electo procurador a Roma. Las noticias sobre brotes de tifus o cólera que devastaban las comunidades indígenas abundan en las cartas enviadas por los misioneros que trabajaban en el Paraguay o en el sur de Chile. El mero hecho de viajar significaba un riesgo ineludible, tanto para el viajero como para los que dejaba atrás. Tras sus viajes por la sierra peruana, Acosta volvía al Colegio de San Pablo en Lima para encontrarse siempre con un registro de muertos, entre estudiantes y sacerdotes. En 1578, Acosta decidió abrir una casa jesuita en Panamá, a fin de que aquellos que viajaban desde Europa pudieran reponer fuerzas. El objetivo era claro: disminuir la alta tasa de mortandad entre los sacerdotes que cruzaban el charco. 
En muchos sentidos, Acosta y sus contemporáneos habitaban un mundo para nosotros reconocible, pero a la vez radicalmente distinto. Naufragios, enfermedades o los elementos eran amenazas constantes; todos viajaban como el caballero del grabado de Durero, con el diablo colgado de la grupa y la muerte recordándole que todo minuto puede ser el último. Y sin embargo, al igual que el caballero, preferían ignorar la advertencia, no mirar el reloj de arena que la muerte les colocaba frente a los ojos, y fijar la vista al frente, con férrea determinación. Sí, sus cartas están llenas de noticias sobre enfermedad y muerte, pero estas noticias aparecen siempre entremezcladas con otras: cobranza de deudas, despacho de negocios, chismes, alegrías, rencores mezquinos y parabienes. En sus cartas, la muerte es un hecho más entre otros. Importante, por cierto, pero no siempre determinante. La muerte era parte de la vida, y su amenaza constante no les impedía embarcarse, amar, odiar o escribir.

Por supuesto, que la posibilidad constante de morir no los paralizara no significa que la muerte no los horrorizara. En El triunfo de la muerte, de Brueghel, la enfermedad aparece como una horda invasora que viene desde la otra orilla a terminar con todo. Batallones y batallones de esqueletos matan, mutilan y violan todo lo que encuentran a su paso, sin importarles si sus víctimas son reyes o campesinos. En la lejanía arden las ciudades y las ruedas de tortura se alzan contra el horizonte como macabros recordatorios de que la enfermedad no solo mata, sino que mata con dolor. Sin embargo, si uno sigue con la vista la acción del cuadro, que zigzaguea desde el tercio superior hasta la esquina inferior derecha, uno se encuentra con que, en medio del horror, hay una pareja de enamorados completamente ajena a todo lo que ocurre a su alrededor. Él se recuesta en el regazo de ella y, perdido en sus ojos, le toca una canción en el laúd mientras ella sostiene la partitura, sin darse cuenta de que detrás un esqueleto los acompaña burlonamente con un violín. Todo el cuadro apunta a este trío, el mejor ejemplo del humor e ironía brueghelianos.

Ironía que también ocurre en otras representaciones de la Enfermedad. Los jóvenes millonarios de Boccaccio se retiran al campo para entretenerse contándose historias de amores y celos mientras los cadáveres se amontonan en las calles de Florencia. Pero como el mismo Boccaccio nos recuerda, poder escapar y mantenerse socialmente distante no es tan solo el privilegio de unos pocos; es también su elección. Otros han decidido que, frente a la amenaza tangible de perder la vida, lo único que vale es aprovecharla mientras se tiene. Carpe diem, parecen gritar estos otros jóvenes, mientras beben, hacen el amor y se van de fiesta. Tanto en Brueghel como en Boccaccio, la muerte, con todo su horror, no puede escapar de un cierto aire burlesco, de carnaval; un aire que desata nuestras capacidades creativas o nuestro lado dionisíaco: los amantes de Brueghel son los únicos — momentáneos- sobrevivientes de un banquete. Fue precisamente escapando de un brote de la peste 
bubónica en Cambridge que Newton se refugió en la granja familiar y vivió su annus mirabilis, entregándonos el cálculo y la teoría de la gravedad.

Nuestra vitalidad creativa está íntimamente ligada a nuestra condición mortal. Es la pareja de Eros y Tánatos, solo que nosotros hemos decidido darle la espalda a Tánatos, relegarlo a la pieza del hospital en lugar de mantenerlo cerca. Pero sin Tánatos, lo erótico no tiene sentido. En la Odisea, Ulises pasa casi siete años prisionero en la isla de Calipso, quien lo ocupa para satisfacer sus deseos carnales. Un día, Mercurio llega con un mensaje de Zeus: es hora de que Ulises vuelva a Ítaca. Calipso reclama airadamente contra la hipocresía de un dios que se siente libre de violar a quien quiera y que ahora le ordena, solo por el hecho de ser mujer, renunciar al hombre que ha escogido. Sabiendo que no tiene opción, va a buscar a Ulises y le dice: eres libre de irte, pero si decides quedarte, te entregaré no solo mi cuerpo divino, sino también la inmortalidad. Ulises, sin embargo, se niega a quedarse. Con mucho tacto (no se rechaza así como así a una deidad) le dice que, aunque ninguna mortal puede siquiera acercarse a su belleza, él prefiere volver a casa y pasar los años de su vejez junto a Penélope. Ulises debe tener, en esos momentos, poco más de 40 años. Aunque aún no es viejo, ya no es un hombre joven. Se encuentra en la edad en que todos empezamos a contemplar nuestra propia mortalidad, a tomar conciencia de que el tiempo parece empezar a apurarse. Y pese a esta conciencia, rechaza el divino tesoro que le es ofrecido, pues en esos siete años se ha dado cuenta que la vida eterna de los dioses es un tormento sin fin para los seres humanos. Mejor volver a casa y pasar lo que nos queda por vivir con aquellos que, como nosotros, también morirán algún día. Solo a ellos podemos entregarnos en cuerpo y alma. Es gracias a la muerte que podemos amar.

\section{III}

Esta paradójica reafirmación de la vida cuando nos enfrentamos a la muerte se ha manifestado de manera explosiva aquí en los Estados Unidos. La muerte de George Floyd le mostró a todo el país de manera irrefutable que Black lives matter. El video del asesinato de Floyd a manos de tres agentes de policía es muy difícil de ver. Son ocho minutos y cuarenta y seis segundos de agonía, durante los cuales un policía blanco le pone la rodilla al cuello a un hombre al que han acusado de un crimen baladí: intentar comprar cigarrillos con un billete falso. Este detalle es importante, pues en casos anteriores que han remecido a este país, otros afroamericanos también han sido asesinados a sangre fría por agentes de policía o civiles armados que consideran imperdonable aquello que ni siquiera puede calificarse como un crimen. En febrero de 2012, Travyon Martin, un adolescente de 17 años, fue asesinado a tiros en Florida por un hombre blanco que encontró sospechoso que el chico llevara el gorro de su polerón puesto. El 2014, Eric Garner murió estrangulado en New York por un policía que lo había detenido por vender ciga- 
rrillos sueltos. "I can't breathe", "No puedo respirar", fueron sus últimas palabras; una frase que ha sido repetida una y otra vez por hombres afroamericanos que se encuentran de golpe en manos de la policía. Una frase que George Floyd repitió una y otra vez, mientras el oficial que lo estaba matando lenta, metódicamente, se burlaba de él diciéndole que si podía hablar, podía respirar. Cerca del final, George Floyd comenzó a llamar a su madre muerta. Como comentó David Chapelle, esa es la reacción de un hombre que se ha dado cuenta de que va a morir ahí, en plena calle, frente a un montón de extraños que, horrorizados, solo atinan a sacar sus teléfonos y grabar sus últimos instantes.

El espectáculo de la vida de George Floyd extinguiéndose lentamente bajo la bota de un policía blanco hizo que la gente se volcara a las calles con indignación. A diferencia de otras veces, ahora era imposible negar lo evidente. La manera metódica en que Floyd fue asesinado volvió concreta, para muchos blancos de clase media, la abstracción del racismo sistémico. Millones de personas, en cientos de ciudades estadounidenses, salieron a manifestarse en contra de la brutalidad policíaca solo para encontrarse con cientos de departamentos de policía dispuestos a ir a la guerra contra el pueblo. Quizás uno de los momentos más emblemáticos fue la orden que Trump le dio a tropas paramilitares agrupadas bajo el Departamento de Seguridad Interior (el Servicio Forestal, la Patrulla de Aduanas y Fronteras) de sacar a la fuerza a un grupo de manifestantes cerca de la Casa Blanca para que él pudiera ir a sacarse una foto, biblia en mano, frente a una iglesia. Las imágenes de un helicóptero de guerra Blackhawk volando bajo, con las aspas inclinadas para levantar la mayor cantidad de basura y así intimidar y dispersar a los manifestantes, imágenes que han sido frecuentes en el Medio Oriente en las últimas décadas, esta vez eran transmitidas desde la capital de los Estados Unidos, y los reprimidos eran ciudadanos estadounidenses que ejercían pacíficamente su derecho constitucional a la protesta. Durante los tres años de su mandato, Trump ha sido acusado repetidamente de fascista, pero nunca ese adjetivo se le pudo aplicar con mayor certeza que esa tarde cuando pisoteó la Constitución para sacarse una foto de campaña.

¿Qué fue distinto esta vez? ¿Por qué la gente salió masivamente a protestar por la muerte de Floyd y no por otros crímenes a sangre fría cometidos por la policía? Porque esta vez las protestas tenían tantos manifestantes blancos como negros y, por primera vez en las encuestas, el movimiento de Black Lives Matter alcanzó una amplia aprobación, mientras el $71 \%$ de los encuestados señalaban al racismo como uno de los principales problemas del país. Hay varios factores que pueden explicar este fenómeno. Uno de ellos es, por cierto, el formidable trabajo que la organización de Black Lives Matter ha hecho durante los últimos cinco años para que su mensaje resuene entre el público general. Pero me parece que el elemento determinante ha sido la pandemia y la rabia y frustración que ha generado entre la 
gente la errática respuesta del gobierno de Trump al colapso del sistema sanitario y de la economía. Los tres años y medio de Trump en la presidencia han estado marcados por la ineptitud y la incompetencia, que nacen de la combinación de su desorbitado ego con un desdén completo por cualquier forma de conocimiento. Esto ha resultado fatal durante esta pandemia. Su mezcla de ignorancia arrogante y crueldad vengativa ha hecho que el país más rico de la historia fuera incapaz de proporcionar mascarillas a sus médicos y enfermeras; que el virus haya devastado comunidades enteras y que la economía más grande del mundo se haya contraído un tercio en apenas dos meses. Escenas impensables, como las filas de kilómetros de largo de gente esperando recibir alimentos gratis en New Jersey o Texas, ponían de relieve las diferencias económicas entre ricos y pobres que no han hecho más que aumentar desde la Gran Recesión del 2008. En Estados Unidos, como en todo el mundo, el virus ha causado un daño económico cuya real magnitud solo entenderemos en los próximos años. Pero, a diferencia de otros lugares, la razón de porqué los Estados Unidos son el país que concentra la mayor tasa de mortandad (tenemos el 22\% de los muertos totales por COVID-19, cuando nuestra población apenas alcanza el 4\% de la población mundial) es el lamentable espectáculo dado por la administración de Trump. El desinterés del presidente en cumplir con las funciones mínimas de un gobierno y su evidente ansiedad por acaparar portadas y minutos en los noticiarios han causado la percepción generalizada de que al gobierno federal no le importan los muertos ni el sufrimiento de la población. Preguntado recientemente por el alto número de casos fatales, Trump respondió: "Es lo que hay" ("It is what it is"). Es cierto que ningún líder mundial tiene buenas opciones en este momento: la economía no puede funcionar si los sistemas hospitalarios colapsan; para que no colapsen, debemos detener el aparato productivo y mantener a la gente en sus hogares. Pero el espectáculo que ha dado la Casa Blanca no tiene parangón en el mundo. Desde febrero, Trump ha dicho que el virus era solo una gripe, o que iba a desaparecer en cuanto llegara la primavera; se ha dedicado a politizar el uso de las máscaras faciales, insistiendo que la gente las usaba para protestar contra su presidencia; no ha dejado de insistir que la hidrocloroquina puede curar la enfermedad e incluso llegó a preguntarse en voz alta si inyectarse desinfectantes domésticos no era la solución al problema.

La evidente incompetencia del gobierno federal nos ha hecho a todos sentir más vulnerables aún frente al coronavirus. La recuperada conciencia de la muerte como una posibilidad constante ha hecho que la población blanca por fin pudiera empatizar con la experiencia de los afroamericanos en este país. Pero además ha puesto en evidencia la injusticia económica a la que han sido expuestos por generaciones. El COVID-19 se ha ensañado particularmente con las comunidades minoritarias. Los afroamericanos y los latinos concentran el triple de casos que los blancos; aproximadamente, la misma proporción con que los hombres negros 
son asesinados por la policía en comparación con los blancos: tres a uno. Lo que el coronavirus ha dejado al descubierto es la crueldad de un sistema que, tanto por razones históricas como por su propio diseño, mantiene a grupos completos sumidos en la pobreza. La historiadora Carol Anderson ha documentado cómo, desde el período conocido como la Reconstrucción (el período que sigue al fin de la Guerra Civil y la emancipación de los esclavos, y que abarca desde 1864 hasta 1877) hasta la elección de Trump, cada triunfo, cada avance de la comunidad negra ha sido seguido por una reacción feroz de la mayoría blanca. Quizás uno de los ejemplos más brutales, no tanto por su violencia como por su largo alcance, sea la reacción frente a la decisión de la Corte Suprema en 1954 conocida como Brown vs. Board of Education. La decisión, unánime, se basaba en la jurisprudencia anterior, un caso de 1896 conocido como Plessy vs. Ferguson, que establecía que la segregación racial era legal toda vez que el mismo nivel de servicios se ofreciera tanto a blancos como a negros. Es decir, las escuelas podían ser exclusivamente para blancos solo si el mismo nivel educacional era ofrecido en las escuelas para la comunidad negra, en lo que se dio en llamar la doctrina de "separados pero iguales". Lo que en 1896 había sido considerado como un triunfo para los supremacistas blancos, en 1954 fue utilizado para desmantelar la doctrina que justificaba la segregación racial: era evidente que los estados, sobre todo en el sur, no invertían la misma cantidad de dinero por alumno en las comunidades afroamericanas. Las escuelas para negros eran, cuando existían, pequeñas, hacinadas, sin calefacción ni baños y con una proporción media de 80 alumnos por profesor, mientras en las escuelas para blancos había 30 alumnos por profesor. Esto creó generaciones enteras de afroamericanos sin escolarización. En Mississipi y Alabama, por ejemplo, en 1954 menos del 50\% de los afroamericanos adultos tenía más de cinco años de escolaridad. Frente a estos hechos, la Corte Suprema consideró que la doctrina de "separados pero iguales" violaba el principio constitucional de igualdad ante la ley dado que las escuelas segregadas eran inherentemente desiguales. Sin embargo, la reacción, sobre todo en los estados del sur, fue devastadora. Muchos municipios desafiaron la resolución del Corte Suprema, negándose a integrar las escuelas. Las asambleas estatales aprobaron ley tras ley contra Brown, lo que llevó a largos y costosos juicios para declarar estas leyes ad hoc inconstitucionales. Algunos distritos escolares simplemente decidieron cerrar todas las escuelas antes que permitir su integración. Para 1963, una década después de Brown, en los estados del sur menos del $2 \%$ de los alumnos afroamericanos asistían a una escuela integrada. Hoy en día, las escuelas siguen estando, en su mayoría, segregadas de facto.

Desde el año 2016, desde la elección de Trump, enseño un curso sobre la historia del racismo para alumnos de primer año, y el ejemplo que pongo para explicar la noción de racismo sistémico es el del rechazo a Brown: Generaciones enteras de afroamericanos impedidos de acceder a la educación y, por lo tanto, privados de 
las oportunidades económicas y sociales que brinda su acceso. Pero podría poner muchos otros casos. La práctica conocida como redlining, por ejemplo, en la que desde 1934 los barrios negros y latinos de las ciudades eran presentados en ciertos mapas federales en rojo, señalando así a los bancos y otros proveedores de servicios que era riesgoso invertir allí. Aunque la práctica fue prohibida en 1968, aún hoy se sienten sus efectos en el desarrollo urbano, con áreas enteras en las ciudades en las que no se encuentra, no digamos ya un hospital o un servicio de urgencias, sino ni siquiera un supermercado u otras tiendas de comida — lo que los urbanistas llaman un food desert - o con una tasa muchísimo menor de afroamericanos y latinos dueños de sus propias viviendas, una brecha que aún ahora no se puede cerrar, afectando gravemente las posibilidades de movilidad social en estos grupos.

El racismo ha informado todo el desarrollo del sistema económico y de políticas públicas estadounidense. Estas políticas han sido de largo alcance y sus resultados se ven con claridad ahora, cuando la economía se desploma debido a la pandemia. Mientras los grupos acomodados (mayoritariamente blancos) pueden encerrarse en sus casas y trabajar desde ahí, los afroamericanos, con un menor acceso a la economía de la información dada la desigualdad educativa que han sufrido por generaciones, han de salir a trabajar, quedando expuestos al contagio, o simplemente pierden sus empleos. En mi vecindario, un vecindario de clase media acomodada, mayoritariamente blanco, la tasa de cesantía debido al COVID-19 llega al 8\%, es decir, poco más del doble del 3,5\% nacional que teníamos en febrero. En otros barrios de Denver, como Commerce City o Five Points, mayoritariamente latinos y negros, la tasa de desempleo es de un 28\%. Como punto de comparación, el máximo al que llegó la tasa nacional de desempleo en abril fue 14,7\%. Como escribió Frederick Douglass en 1881, la esclavitud desapareció hace tiempo, pero su sombra aún se cierne sobre el país y envenena, en mayor o menor medida, la atmósfera moral de todas las áreas de la república. La bota del policía blanco que aplastó la garganta de George Floyd es el símbolo de un sistema racista que ha estado aplastando a millones de hombres y mujeres por más de un siglo en este país.

\section{IV}

En los Estados Unidos, clase y raza están profundamente imbricadas. Desde este punto de vista, las manifestaciones contra el racismo aquí son, en cierto sentido, parte de un malestar generalizado contra las democracias liberales y el sistema económico que las sostiene, el capitalismo post-colonial. Esta pandemia llegó en un momento en el que el pacto social mismo ha estado en tela de juicio durante los últimos diez años. Desde el 2011 en adelante, movimientos populares como los indignados, Occupy Wall Street, o las protestas sociales en Chile, junto al alza de los movimientos populistas en todo el mundo, hablan de un sistema en crisis, crisis aprovechada no solo por aquellos que quieren una redistribución de la riqueza y el 
poder, sino también —y quizás de forma más efectiva - por aquellos que buscan su concentración. Los autócratas como Orban, Erdogan o Maduro han evolucionado. Ya no son más los dictadores al estilo Pinochet. Su modelo es Putin: un autócrata que ha mantenido la cáscara de la democracia, mientras aumenta su poder y su control sobre las instituciones nacionales a través del clientelismo.

La democracia liberal es un experimento reciente en la historia humana, un experimento basado en ideas y prejuicios propios de la Ilustración europea. Los tres principios básicos que sostienen la promesa de la democracia — y que la hacen tan atractiva - son la igualdad, la justicia y la libertad. Estos principios están consagrados por los documentos fundacionales de las democracias modernas, la Declaración de los derechos del hombre aprobada por la Asamblea Nacional Constituyente francesa en 1789 y la Declaración de independencia de los Estados Unidos (1776), que además agregaba como derecho fundamental la búsqueda de la felicidad. A pesar de estas declaraciones de principio, la historia de las democracias modernas ha sido la historia de la lucha por extender estos derechos y garantías a la mayoría de la población, excluida explícitamente en un comienzo de la participación democrática. Los fundadores de los Estados Unidos eran todos hombres, todos blancos, todos de la misma clase social y, con contadas excepciones, todos esclavistas. En Francia en 1789, algunos affranchis haitianos, como Julien Raimond and Jacques Vincent Ogé, encararon a los miembros de la Asamblea Nacional, instándolos a darle un sentido concreto a sus principios y declaraciones reconociendo la igualdad de los hombres negros. La Asamblea respondió con un gesto conciliatorio pero profundamente conservador: se le otorgó la ciudadanía a un puñado de affranchis y de afrohaitianos libres, pero se mantuvo la esclavitud. Esto desencadenó la primera revolución independentista en América Latina, un hecho de capital importancia para nosotros: Sin la ayuda de Haití, un derrotado Bolívar no podría haberse rearmado para intentar la liberación de la Gran Colombia. La única condición que se le pidió fue abolir la esclavitud en los territorios que liberase.

Pero la ampliación de los derechos fue siempre lenta, una promesa para el reino del otro mundo antes que para el de este. La esclavitud perduró en los Estados Unidos hasta 1864; en Puerto Rico, hasta 1873 y en Cuba hasta 1880. Brasil, donde en 1800 la mitad de la población era esclava, no abolió la esclavitud hasta 1888. Ni hablar de los derechos de las mujeres: el voto femenino tuvo que esperar hasta bien entrado el siglo XX en nuestro hemisferio. Aún hoy los derechos reproductivos están lejos de ser universalmente reconocidos como derechos humanos. La igualdad matrimonial, independiente de la orientación sexual, sigue siendo una utopía en buena parte de las democracias occidentales.

La historia de las democracias liberales ha sido así una lucha lenta, espasmódica, y demasiado frecuentemente sangrienta por aumentar el número de aquellos que 
gozan de los derechos y garantías prometidos por el liberalismo. Pero los apólogos de este lo han presentado como una constante ampliación de las libertades humanas, sobre todo cuando la comparación era con las repúblicas de la órbita soviética, con su evidente falta de libertad política. Para el pensamiento liberal, la libertad, como lo planteó John Stuart Mill, es la condición de necesidad para la felicidad humana. Solo aquellos que son libres pueden desarrollar su potencial creativo al máximo. Sin embargo, como se dio cuenta Marx, nadie puede ser libre en tanto viva en la pobreza, con hambre y sin educación. Sin una cierta medida de equidad social, de igualdad, la libertad como la entendía Mill es solo un slogan, o más exactamente, un derecho garantizado solo para la minoría dirigente. Y si bien el capitalismo y las democracias liberales han reducido los niveles globales de pobreza, la promesa por la igualdad sigue y seguirá siendo una promesa incumplida. En parte, esto se debe a un problema estructural: la mutua incompatibilidad de los valores liberales. Como notó Isaiah Berlin, los filósofos ilustrados partieron de una premisa falsa: que todas las personas buscan más o menos las mismas cosas, y que estos objetivos no se contradicen mutuamente. Todos quieren libertad, por ejemplo, y todos quieren igualdad. Pero para que haya igualdad, es necesario regular la libertad de los individuos; mientras que para que haya mayor libertad individual es necesario sacrificar el ideal igualitario. La tensión política en las democracias liberales durante el llamado siglo XX corto (1945-1989) se puede explicar así: las izquierdas ponían el énfasis en la igualdad — la primacía de la noción del bien comúnmientras las derechas insistían en la primacía valórica de la libertad individual y, sobre todo, económica. La idea de los filósofos alemanes de post-guerra (que tanto influyeron en los políticos de la transición chilena) de que era posible un consenso que aliviara esta tensión queda desmentida de inmediato con una mirada fugaz a la historia del siglo pasado, sin duda el más sangriento en la historia de la humanidad.

Quizás el punto de inflexión pueda situarse en un tiempo y un lugar muy precisos: La década de los 70; la Escuela de Economía de la Universidad de Chicago. Algunas de las ideas centrales de Milton Friedman, como el laissez-faire económico y, fundamentalmente, la noción de que las empresas y corporaciones carecen de responsabilidad moral alguna como no sea maximizar la ganancia de los inversores, han demostrado ser profundamente destructivas. Adoptadas como un mantra por Ronald Reagan y enseñadas en todas las escuelas de economía de los Estados Unidos durante las últimas cuatro décadas, nos han llevado al momento que vivimos hoy: una de las eras de mayor desigualdad económica desde los tiempos del imperio romano; con el agravante de que el carácter depredador del capitalismo (liberado por Friedman de todo escrúpulo moral) ha destruido sistemática y conscientemente el medio ambiente, legándonos una crisis existencial ante la que los más desposeídos se hallan infinitamente más expuestos. Y los desposeídos somos cada vez más. De acuerdo al Brookings Institute, en el año 2016, el 20\% más rico 
de los Estados Unidos concentraba el 77\% de la riqueza total del país, es decir, más del triple de la riqueza total de la clase media norteamericana. Incluso dentro de esta clase privilegiada las diferencias son enormes: El 1\% más rico concentraba ese año casi el 30\% de la riqueza total. Y esto ocurre en el país más rico de la historia; en el país en el que incluso ser pobre resulta más atractivo que la miseria y la violencia en que viven millones y millones de personas en el resto del mundo.

En las democracias liberales, la acumulación del capital siempre ha venido de la mano con la acumulación del poder político, desde los tiempos de Jefferson y Roberspierre. Sin embargo, desde la Gran Recesión del 2008, la diferencia entre los que tienen y los que no tienen se ha vuelto cada vez más evidente. Según el mismo reporte del Brookings Institute, en los Estados Unidos solo el 20\% más rico se ha recuperado de la recesión económica. El 80\% restante es hoy más pobre de lo que era hace 12 años. Es imposible separar este hecho del desencanto global con la democracia y de la baja participación electoral en casi todos los países del mundo. A esto hay que sumarle el que hemos llegado a un momento crítico con el estado del medio ambiente, con cambios aparentemente irreversibles y que comienzan a afectar a la población: cosechas perdidas, ciudades que deben racionar el agua, temperaturas extremas, incendios descontrolados, enfermedades tropicales como el dengue, el zika o el chikunguña que amplían año tras año las zonas geográficas que afectan. Es en este contexto que llega la pandemia. No es casualidad que desde comienzos de siglo, tres coronavirus distintos y muy mortíferos hayan dado el salto desde sus reservorios naturales a los humanos: El SARS el año 2002, el MERS el 2012, y ahora COVID-19 el año pasado. Esta pandemia también es el legado del capitalismo depredador y descontrolado, de su apetito voraz por recursos naturales y su indiferencia inmoral por el medio ambiente.

El resultado ha sido no solo que estamos todos a merced de un virus para el cual aún no tenemos ningún tratamiento efectivo y del cual aún no sabemos demasiado. Porque aquí también se manifiesta la pronunciada desigualdad que el capitalismo de fines del siglo XX nos ha heredado. Los más vulnerables son aquellos que tienen condiciones asociadas a la pobreza y la falta de educación, como la obesidad y la diabetes; aquellos que no pueden quedarse en casa y deben salir a buscarse la vida día a día; aquellos que no pueden acceder más que a comidas ultraprocesadas y a una dieta basada en calorías baratas. Visto así, no puede sorprender que el virus se haya cebado sobre las minorías en este país. El virus no ha hecho más que explotar las carencias estructurales del sistema.

May you live in interesting times, reza una maldición británica. Mientras redacto estas notas, el cambio climático ha desatado su furia destructiva. El Oeste de los Estados 
Unidos está en llamas. Medio millón de personas han tenido que ser evacuadas en Oregon; pueblos enteros han sido arrasados en California; incendios forestales de magnitud histórica en Colorado. La luz se ha vuelto rojiza y llueve ceniza sobre Denver. Desde la ventana de mi escritorio hace semanas que no se ven las montañas. Mientras tanto, Trump hace esfuerzos denodados por interferir en las elecciones y aún no hay un atisbo de vacuna para el COVID-19, cuyos casos confirmados superan ya los seis millones en Estados Unidos. La violencia política comienza a volverse letal en un país en el que hay más armas que habitantes, aumentada por la crispación que produce esta sensación de fin de mundo. Se nos viene un largo y oscuro invierno. Pero las profecías me asquean y no puedo decir más.

Dénver

11 de septiembre de 2020 